\title{
Stage I Gestational Trophoblastic Neoplasm AJCC v8
}

National Cancer Institute

\section{Source}

National Cancer Institute. Stage I Gestational Trophoblastic Neoplasm A/CC v8. NCI

Thesaurus. Code C140034.

Stage I includes: T1, M0. T1: Gestational trophoblastic neoplasm in which the tumor is confined to uterus. MO: No distant metastasis. (AJCC 8th Ed.) 